\title{
Advantages of nerve-sparing intrastromal total abdominal hysterectomy
}

This article was published in the following Dove Press journal:

International Journal of Women's Health

21 January 2013

Number of times this article has been viewed

\section{Daryoosh Samimi' \\ Afdal Allam ${ }^{2}$ \\ Robert Devereaux ${ }^{2}$ \\ William $\mathrm{Han}^{2}$ \\ Mark Monroe ${ }^{2}$ \\ 'Department of Obstetrics and Gynecology, Keck School of Medicine, University of Southern California, Los Angeles, CA, ${ }^{2}$ Department of Obstetrics and Gynecology, Fountain Valley Regional Hospital, Fountain Valley, CA, USA}

\section{Video abstract}

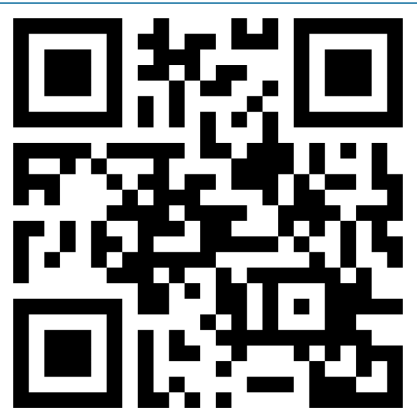

Point your SmartPhone at the code above. If you have a QR code reader the video abstract will appear. Or use: http://dvpr.es//kth4

Correspondence: Daryoosh Samimi USWomen Institute,

PO Box 9870, Fountain Valley,

CA 92728, USA

Tel + I 7|4 5463898

Fax + I 714916555I

Email dsamimi19@hotmail.com

Background: The purpose of the prospective study was to evaluate the effect of the nervesparing intrastromal abdominal hysterectomy bilateral salpingo-oophorectomy (ISTAH-BSO) on intraoperative, and postoperative complications namely blood loss and length of hospital stay. Methods: Forty female patients were allocated by a block randomization method into a study group and a control group. The study group consisted of 20 patients who underwent ISTAHBSO over a 2-year period. The control group included 20 patients who underwent conventional hysterectomy by the same surgeon during the same time frame. Both groups were followed for outcomes of interest, which included length of hospital stay, blood loss, and surgical complications. The participants in both groups were as similar as possible with respect to all known or unknown factors that might affect the study outcome.

Results: Postoperative hemoglobin levels were higher in the study group (blood loss $1.0 \mathrm{~g} / \mathrm{dL}$ versus $1.4 \mathrm{~g} / \mathrm{dL}$ in control group). Average hospital stay was significantly shorter in the study group (2.7 days versus 3.15 days in the control group, $P=0.028$ ). No significant complications such as urinary fistula, vaginal vault prolapse, blood transfusion, or postoperative infections were identified in the study group.

Conclusion: The nerve-sparing ISTAH-BSO procedure described in this study has the potential to reduce length of hospital stay after abdominal hysterectomy by reducing blood loss and postoperative complications. Follow-up observations suggest that urinary function and sexual satisfaction are also preserved. Since this research, 175 cases have been performed, with an average of 5 years of follow-up. The outcomes of these cases have been reported as similar.

Keywords: cervical cancer, support system, nerve sparing, complications, blood loss, hospital stay

\section{Introduction}

In traditional hysterectomies, surgeons generally remove the uterus by cutting the uterosacral ligaments, the cardinal ligament of Mackenrodt, and the uterine vessels before entering the vaginal fornix. Nerves in the Frankenhauser's nerve plexus and the vesical plexus, as well as other downstream nerves, may sustain significant damage. ${ }^{1-3}$ Additionally, the fibrous condensation in the endopelvic fascia is severed so that it no longer supports the vaginal vault. ${ }^{4,5}$ Conventional hysterectomy complications as listed by Copeland and Jarrell are remarkable for febrile morbidity, transfusion, lifethreatening events, rehospitalization, and death. ${ }^{6}$

In contrast, intrastromal total abdominal hysterectomy (ISTAH) is a novel surgical method designed to maintain the integrity of the cardinal, uterosacral, and 
endopelvic ligaments. In the meantime, the cervix and uterus are removed while the functional part of the cervical stroma or pericervical ring is left intact. ${ }^{7}$

Nerve-sparing intrastromal abdominal hysterectomy may reduce blood loss and avoid many of these complications. ${ }^{5,8}$ To evaluate the effectiveness and tolerability of this type of surgery, we designed a study to evaluate intrastromal total abdominal hysterectomy (ISTAH-BSO). The ISTAH-BSO procedure was compared with traditional hysterectomy with regard to blood loss and length of hospital stay. In addition, possible interference with sexual and/or bladder function postoperatively was assessed..$^{5,8}$

\section{Materials and methods}

Forty women were enrolled in this study. The study group consisted of 20 patients who underwent ISTAH-BSO performed by a single surgeon (DS) at Fountain Valley Regional Hospital over a 2-year period. Inclusion criteria included both medically and surgically stable patients presenting with symptoms that, in the opinion of the gynecologist and patient, justified hysterectomy. Indications for hysterectomy were intramural or submucosal uterine leiomyoma, anemia, chronic menorrhagia, chronic metrorrhagia, amenorrhea, and pelvic endometriosis. ${ }^{5,9}$ Written informed consent was obtained from all women who agreed to participate in the study and to attend a follow-up visit one year later. Exclusion criteria included medically and/or surgically unstable patients. Patients with a recent history of alcohol or narcotic use as determined by preoperative assessment were excluded from the study.

Outcomes in the study group were compared with outcomes in a control group of 20 patients who had undergone conventional abdominal hysterectomy procedures performed by the same surgeon at Fountain Valley Regional Hospital. 1,9,10 The study protocol was approved by the Central Investigational Review Board.

The founder of randomized controlled trials (Fisher) first introduced the idea of randomization, the academic community has deemed randomization an essential tool for unbiased comparisons of treatment groups. ${ }^{11}$ Five years after Fisher's introductory paper, the first randomized controlled trial involving tuberculosis was conducted involving a total of 24 participants that were each paired (ie, 12 comparable pairs) by randomization. In our study, both the control group and study group candidates were chosen by a block randomization method. This randomization method was chosen to produce a sample size with balanced baseline characteristics between the treatment and control groups.
The ISTAH-BSO is performed as follows. The patient is placed comfortably in Allen stirrups with the buttocks brought to the edge of the "broken" operating table. The knees are separated about 90 degrees. The thighs are elevated relative to the abdomen. The patient is draped to allow access to the vaginal introitus and external urethral meatus. ${ }^{6}$ In most cases, a low transverse incision is made. In rare cases, a midline incision is utilized. Any existing surgical scar tissue is removed at that time. After the abdominal cavity is entered, an examination and palpation is carried out, and the bowel is packed out of the way.

The round ligaments are severed on both sides about $2 \mathrm{~cm}$ away from the cornual end of the uterus. These severed ends are then ligated. This manipulation concurrently opens the broad ligaments so that an anterior vesical flap of peritoneum can be formed. If the adnexae are to remain intact, an avascular area is found in the broad ligament near the uterus. This area is entered with either a finger or a curved clamp. The tube and the ovarian ligament are clamped, severed, and ligated with a suture. If the ovaries are to be removed, the infundibulopelvic ligament is clamped, severed, and ligated with a suture from the side of the uterus. After the main uterine vessels are skeletonized, they are triple-clamped and cut bilaterally. The lowest clamp is placed first below the level of the internal os and positioned at a right angle to the lower uterine isthmus. The other two clamps are secured by No 0 delayed absorbable suture ligatures.

To perform ISTAH-BSO, a vasopressin solution is diluted with sterile normal saline to a final concentration of $0.4 \mathrm{U} / \mathrm{mL}$. The vasopressin solution is then injected into the peripheral portion of the cervix (transabdominally) until blanching in this area is observed. Using a thermo-electric or laser knife, a circumferential incision is made just cephalad to the pericervical ring and stroma at the level of the ligated uterine arteries, below the internal os or isthmus (Figure 1 and Figure 2). ${ }^{9-13}$ The incision must be performed by cutting and sometimes coagulation in the case of bleeding. The pericervical ring and peripheral portion of the cervix must be protected (Figure 2). ${ }^{3,4}$ The circumferential incision must travel through the pericervical ring and stroma until the epithelium of the fornix is visualized. The closing suture must be fixed immediately to the surgical margin of the fornix. Cutting and suturing must be performed by a continuous interlocking technique. Bleeding is controlled by mild to moderate traction of the uterus. The uterus, cervix, and cervical guider will be removed altogether abdominally.

A cervical guider (patent pending) is used to assist in the navigation of the pericervical ring during the procedure. The 


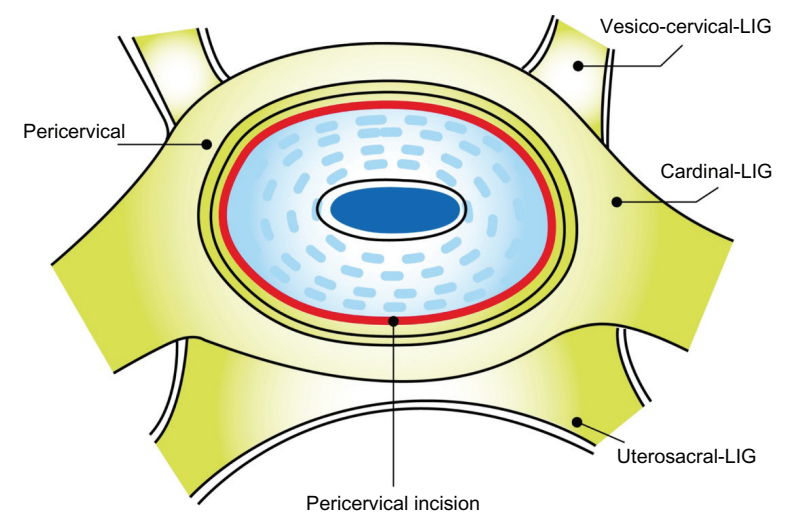

Figure I Transverse cut presentation nerve sparing hysterectomy. Abbreviation: LIG, ligament.

cervical guider is a small disposable device used to protect and guide the cervical direction. This device is placed on the cervix prior to initialization of ISTAH-BSO.

Closure of the vaginal fornix is accomplished by a continuous suturing technique. The rest of the closure is performed from the vaginal side toward cephalad by using a spiral technique all through the abdominal side. After the upper margin of the pericervical ring is closed, the intact cardinal ligaments, uterosacral ligaments, and endopelvic fascia are reinforced by round ligaments. The peritoneal flaps are raised and their surfaces are covered. Adequate instruction and training is necessary to perform this hysterectomy method.

In the control group, conventional abdominal hysterectomy was performed. In this procedure, the uterus was removed by cutting the uterosacral ligaments, the cardinal ligament of Mackenrodt, and the uterine vessel before

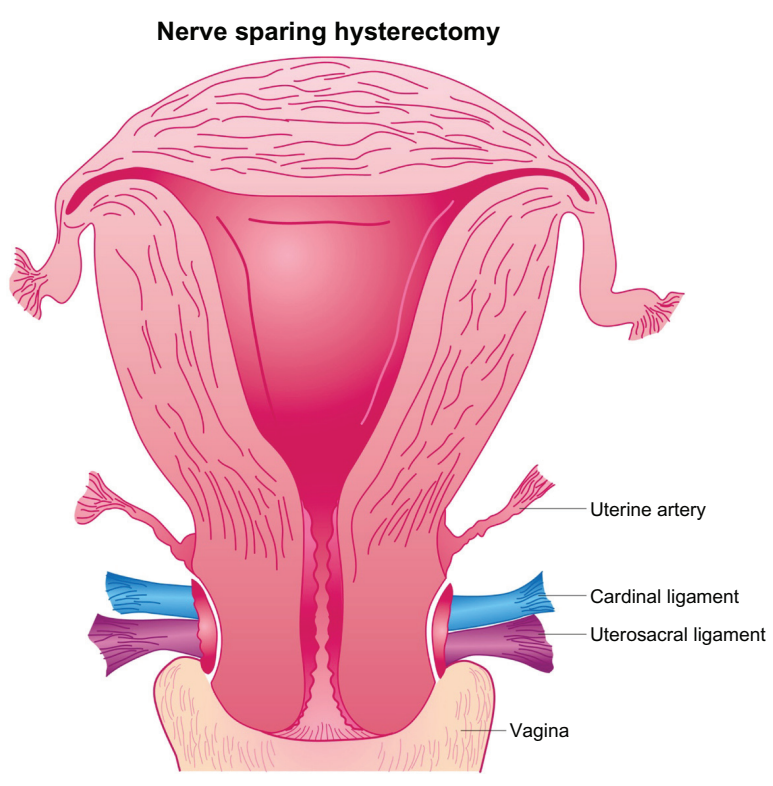

Figure 2 Vertical presentation nerve sparing hysterectomy. entering the vaginal cavity. ${ }^{8,10}$ The uterus was then severed from the vagina in a circular manner at the cervicovaginal junction. ${ }^{1,2,4}$ To access this area, the bladder was either pushed down or dissected free of its attachments.

\section{Results}

Patients in the study group did not differ significantly from controls in age or body weight. The groups were also similar with respect to indications for hysterectomy (Table 1).

The pathological specimen and report confirmed that the whole cervix was removed along with the uterus during ISTAH-BSO in all cases. Patients who received ISTAH-BSO recovered more quickly than the controls, as reflected by a significant reduction in the number of hospitalization days (Table 2). On average, the controls required significantly ( $P=0.03)$ longer hospitalization ( 3.15 days) than patients in the study group ( 2.70 days). There was also a trend towards lower blood loss that neared statistical significance in the study patients. The controls showed a mean hemoglobin decrease of $1.35 \mathrm{~g} / \mathrm{dL}(11.38 \%)$ when before and after hysterectomy values were compared, while the study group showed a decrease of $0.91 \mathrm{~g} / \mathrm{dL}(8 \%, P=0.077)$.

No patients in the study group of 20 patients showed any of the classic intraoperative or postoperative complications of hysterectomy. ${ }^{6}, 14$ Bleeding from the vaginal margin at the end of surgery occurred in only one patient. Vaginal bleeding was treated with one stitch, and the stitching procedure was completed before the patient left the operating room. No postoperative morbidity or fatalities occurred among patients who underwent ISTAH-BSO.

\section{Discussion}

\section{Effect on length of stay}

This study confirms that the ISTAH-BSO procedure has advantages over conventional abdominal hysterectomy. In our study of ISTAH-BSO, the mean length of stay was 2.7 days, which is shorter than the typical length of stay for total abdominal hysterectomy. ${ }^{7,15}$ The mean length of stay of 3.15 days found for controls in our study is consistent with the 3.9-4.4 days reported in the literature for conventional abdominal hysterectomy. ${ }^{7,16}$ The shorter length of stay may relate to the less traumatic nature of the ISTAH-BSO procedure, which our data indicate may result in less blood loss than conventional abdominal hysterectomy.

\section{Effect on postoperative complications}

The pubocervical fascia prevents herniation of the bladder and urethra into the vagina. The conventional procedure may 
Table I Patient demographics in the study group versus controls

\begin{tabular}{llll}
\hline & $\begin{array}{l}\text { Study group } \\
(\mathbf{n}=\mathbf{2 0})\end{array}$ & $\begin{array}{l}\text { Control group } \\
(\mathbf{n}=\mathbf{2 0})\end{array}$ & P value \\
\hline Mean age, years (range) & $51.5 \pm 10.3(41-74)$ & $49.3 \pm 5.3(43-64)$ & NS \\
Mean weight \pm SD, Ib (range) & $173.4 \pm 39.3(117-238)$ & $162.6 \pm 32.2(107-205)$ & NS \\
Indication $(\mathbf{n})$ & & & \\
Chronic pelvic pain & 19 & 18 & NS \\
Intramural or submucosal uterine leiomyoma & 17 & 18 & NS \\
Anemia & 6 & 8 & NS \\
Pelvic endometriosis & 15 & 14 & NS \\
\hline
\end{tabular}

Abbreviations: NS, no statistically significant difference; SD, standard deviation.

lead to chronic or progressive damage of the pelvic nervous system or pelvic supportive structure that results in incontinence in the years following the procedure. ${ }^{5,10}$ The mean rate of intraoperative and postoperative complications for total abdominal hysterectomy has been reported as $40 \%$ before discharge and $9 \%$ after discharge. ${ }^{17}$ The hysterectomies that have the highest potential for morbidity and mortality may include those with definitive amenorrhea. ${ }^{18}$ Complications commonly include pyrexia, blood loss requiring transfusion, urine retention, wound hematoma, wound infection, and persistent pain. ${ }^{13,17}$ None of these complications occurred in patients who had ISTAH-BSO. Bleeding in a single patient required only one stitch.

\section{Effect on sexual and bladder dysfunction}

It has been estimated that women who undergo conventional hysterectomy have up to a $60 \%$ greater risk of developing voiding dysfunction and urinary incontinence later in life than those who do not undergo the procedure. ${ }^{5,19,20}$ This may relate to the lateral support of the uterus by the uterosacral and cardinal ligaments and the posterior support that these ligaments provide to the cervix. In addition, these attachments provide direct and indirect support to the bladder and urethra. The primary function of these suspensory mechanisms is to support the upper urethra and urethrovesical junction. ${ }^{6,19}$ In addition, the fascia of the bladder and the anterior vaginal wall are fused to form the pubocervical fascia. ${ }^{6,19}$ The pubocervical fascia prevents herniation of the bladder and urethra into the vagina. Meanwhile, the cardinal and uterosacral complex and pericervical rings support vaginal nerve function. ${ }^{1,2,4}$
It is noteworthy that the conventional hysterectomy procedure may lead to chronic or progressive damage of the pelvic nervous system or pelvic supportive structure that results in future incontinence which, in turn, may also have a negative effect on sexual function. . $^{5,82}$

ISTAH-BSO is proposed as an alternative to reduce the risk of sexual and bladder dysfunction. During the procedure, neither the cardinal ligaments nor the uterosacral ligaments are severed, thereby avoiding injury to the Frankenhauser's nerve plexus, vesical nerve plexus, and uterovaginal nerve plexus, all of which communicate with each other. ${ }^{1,25}$ Furthermore, using this procedure, the outer stroma of the cervix is the pericervical ring, and the cervix is removed from this bed. This should also be helpful in preventing future cervical cancer. ${ }^{3,9,22}$

Some confusion exists about the differences between intrafascial abdominal hysterectomy and intrastromal hysterectomy. Intrafascial abdominal hysterectomy involves an incision and clamping of the pubocervical fascia. As the dissection progresses, the dense attachment of cardinal and uterosacral ligaments is severed, interrupting a major support system and nerve plexuses. ${ }^{5,23}$ ISTAH-BSO, on the other hand, involves incision into the cervical stroma on the top of the pericervical ring. Without cutting or clamping the cardinal ligament, uterosacral ligament, and fascia, the cervix and uterus are removed from the pericervical ring. This method protects the support system and neural plexuses surrounding the ring. ${ }^{5,23}$

Hysterectomy has been reported by some investigators to have a negative effect on sexual satisfaction..$^{5,821}$ In several

Table 2 Outcomes: length of hospital stay and hemoglobin levels

\begin{tabular}{|c|c|c|c|}
\hline Outcome & $\begin{array}{l}\text { Study group } \\
(n=20)\end{array}$ & $\begin{array}{l}\text { Control group } \\
(n=20)\end{array}$ & $P$ value \\
\hline Mean change \pm SD in hemoglobin levels, g/dL (range) & $\begin{array}{l}-0.91 \pm 0.59 \\
(-0.1 \text { to }-2.2)\end{array}$ & $\begin{array}{l}-1.35 \pm 0.91 \\
(-0.4 \text { to }-46)\end{array}$ & 0.077 \\
\hline Mean length of hospital stay $\pm S D$, days (range) & $2.70 \pm 0.47(2-3)$ & $3.15 \pm 0.75(2-5)$ & 0.028 \\
\hline
\end{tabular}

Abbreviation: SD, standard deviation. 
studies, post-abdominal hysterectomy sexual complications ranged from $28 \%$ to $37 \% .{ }^{5,8}$ In the entire series of 175 cases, 73 patients agreed to complete a questionnaire related to their sexual satisfaction before undergoing the nerve-sparing ISTAH-BSO. Of the 73 respondents, 52 patients reported that they experienced sexual satisfaction, whereas 21 patients answered that they lacked sexual satisfaction. Postoperative follow-up showed that ITSAH-BSO did not affect rates of sexual satisfaction among responders.

ISTAH-BSO may help to preserve bladder function, as indicated by the responses of 20 patients who had undergone ISTAH-BSO to a questionnaire that investigated their bladder function. ${ }^{18,24,25}$ Fifteen of 20 patients responded that they suffered stress urinary incontinence before the ISTAH-BSO procedure, while the five remaining patients reported they did not have bladder problems. Two of the 15 stated that they had anti-incontinence surgery prior to ISTAH-BSO. Although these two patients were still encountering continuous bladder leakage, they indicated that they were not interested in having a procedure done to treat their incontinence.

The 13 remaining patients had only stress urinary incontinence (prior to ISTAH-BSO), as confirmed by physical examination and urodynamic testing. All 15 patients declined to have anti-incontinence procedures. In follow-up phone calls 3 years after completion of ISTAH-BSO, 18 patients responded that they had maintained continent bladder function throughout the year since their ISTAH-BSO. The other two patients remained incontinent due to intrinsic sphincter deficiency, as verified by history, physical examination, and urodynamic testing. ISTAH-BSO has shown the capability to correct stress urinary incontinence in patients, because it preserves nerve fibers and the support system following removal of the uterus. ${ }^{9,12,23,24}$ Furthermore, ISTAH-BSO keeps the endopelvic fascia intact. Hence, bladder function is maintained, and preservation of the nerves helps prevent stress urinary incontinence.

\section{Conclusion}

Nerve-sparing ISTAH-BSO appears to reduce complications, shorten hospital length of stay, and minimize blood loss. It may also help to preserve bladder and sexual function and prevent cervical cancer. It is an indispensable abdominal method that could theoretically be used for all patients requiring hysterectomy. If a surgeon encounters bleeding, perforation, or injury to adjacent organs during laparoscopic, robotic, or vaginal hysterectomy, the surgeon must employ ISTAH because it is an abdominal method. The supracervical hysterectomy is performed when the surgeon has major difficulty removing the cervix. The surgeon can cut the uterus from below the internal os and remove the uterus. However, performing a supracervical hysterectomy is not proven to prevent cervical cancer, and therefore poses a significant risk to patient safety.

\section{Acknowledgments}

The authors wish to thank SG Phillips, Project House Inc, for manuscript editing, K Dougherty for data analysis, and JS Samimi for medical coding.

\section{Disclosure}

The authors report no conflicts of interest in this work.

\section{References}

1. Cunningham G, Gant N, Leveno K, Gilstrap L III, Hauth J, Wenstrom K William 's Obstetrics, 21st ed. New York, NY: McGraw-Hill; 2001.

2. Williams PL, Warwick R. Gray's Anatomy, 36th ed. London, UK: Churchill Livingstone; 2005.

3. Greer B, Koh W. ACOG Practice bulletin. Diagnosis and treatment of cervical carcinomas. Int J Gynaecol Obstet, 2002;78(1):79-91.

4. Stenchever MA, Droegemueller W, Herbst AL, Mishell D Jr, editors. Comprehensive Gynecology, 4th ed. Philadelphia, PA: Mosby Company; 2001

5. Rock JA, Thompson JD, editors. TeLinde's Operative Gynecology, 7th ed. Philadelphia, PA: Lippincott Williams \& Wilkins; 2005.

6. Copeland L, Jarrell J. Textbook of Gynecology, 2nd ed. Philadelphia, PA: WB Saunders Company; 1993.

7. Summitt RL, Stovall TG, Steege JF, Lipscomb GH. A multicenter randomized comparison of laparoscopically assisted vaginal hysterectomy and abdominal hysterectomy in abdominal hysterectomy candidates. Obstet Gynecol. 1998;92(3):321-326.

8. Berek JS, Novak E. Berek and Novak's Gynecology, 14th ed Philadelphia, PA; Lippincott Williams \& Wilkins; 2006.

9. Samimi D, Devereaux RA, Monroe MN, Allam A, Gendler SE, Roshan R. A randomized trial of intrastromal abdominal hysterectomy to support shorter hospital stay and prevent blood loss and disturbing the pelvic support. Abstract presented at 51st Annual Clinical Meeting of the American College of Obstetrics and Gynecology, New Orleans, LA, April 26-30, 2003.

10. Falcone T, Walters M. Hysterectomy for benign disease. Obstet Gynecol. 2008;111(3):753-768.

11. Kang M, Ragan B, Park, J. Issues in Outcomes Research: An Overview of Randomization Techniques for Clinical Trials. J Athl Train 2008;43(2):215-221

12. Rossi AC, D'Addario V. Laser therapy and serial amnioreduction as treatment for twin-twin transfusion syndrome: a meta-analysis and review of literature. Am J Obstet Gynecol. 2008;198(2):147-152.

13. Samimi D, Drukker B, Tanagho EA. Outpatient Burch-sling procedure: a nerve sparing method for correction of female urinary incontinence. J Soc Gynecol Investig. 2002;9 Suppl:883.

14. Harris MB, Olive DL. Changing hysterectomy patterns after introduction of laparoscopically assisted vaginal hysterectomy. Am J Obstet Gynecol. 1994;171(2):340-344

15. Jacoby VL, Autry A, Jacobson, G, Domush R, Nakagawa S, Jacoby A. Nationwide use of laparoscopic hysterectomy compared with abdominal and vaginal approaches. Obstet Gynecol. 2009;114(5):1041-1055.

16. Thakar R, Ayers S, Clarkson P, et al. Outcomes after total versus subtotal abdominal hysterectomy. $N$ Engl J Med. 2002;347(17): $1318-1325$.

17. Dorsey JH, Steinberg EP, Holtz PM. Clinical indications for hysterectomy route: patient characteristics or physician preference? Am JObstet Gynecol. 1995;173(5):1452-1460. 
18. American College of Obstetricians and Gynecologists Committee on Adolescent Health Care. ACOG Committee Opinion No 448: Menstrual manipulation for adolescents with disabilities. Obstet Gynecol. 2009;114(6):1428-1431.

19. Brown JS, Sawaya G, Thom DH, Grady D. Hysterectomy and urinary incontinence: a systematic review. Lancet. 2000;356(9229):535-539.

20. Danforth KN, Townsend MK, Lifford K, Curhan GC, Resnick NM, Grodstein F. Risk factors for urinary incontinence among middle-aged women. Am J Obstet Gynecol. 2006;194(2):339-345.

21. Gross CP, Nicholson W, Powe NR. Factors affecting prophylactic oophorectomy in postmenopausal women. Obstet Gynecol. 1999; 94(6):962-968.
22. Poad D, Arnold EP. Sexual function after pelvic surgery in women. Aust N Z J Obstet Gynaecol. 1994;34(4):471-474.

23. Ostergard, DR, Berman M, Yee B, Schmitt W. Atlas of Gynecologic Surgery. Philadelphia, PA: WB Saunders Company; 2000.

24. Samimi D. The closed Burch procedure - outpatient - with no laparotomy or laproscopy. Presented at the 46th Annual Clinical Meeting of the American College of Obstetrics and Gynecology, New Orleans, Louisiana, LA, May 9-13, 1998.

25. Samimi D. Performing a bloodless, nerve sparing total abdominal hysterectomy without disturbing the pelvic support system. Poster 884 presented at the 49th Annual Meeting of the Society for Gynecologic Investigation, Los Angeles, CA, March 20-23, 2002.

\section{Publish your work in this journal}

The International Journal of Women's Health is an international, peerreviewed open-access journal publishing original research, reports, editorials, reviews and commentaries on all aspects of women's healthcare including gynecology, obstetrics, and breast cancer. The manuscript management system is completely online and includes a very quick and fair peer-review system, which is all easy to use. Visit http://www.dovepress.com/testimonials.php to read real quotes from published authors.

Submit your manuscript here: http://www.dovepress.com/international-journal-of-womens-health-journal 